\title{
Are atmospheric PBDE levels declining in central Europe? Examination of the seasonal and semi-long-term variations, gas-particle partitioning and implications for long-range atmospheric transport
}

\author{
Céline Degrendele $^{1}$, Jake Wilson ${ }^{2}$, Petr Kukučka ${ }^{1}$, Jana Klánová $^{1}$, and Gerhard Lammel ${ }^{1,2}$ \\ ${ }^{1}$ Masaryk University, Research Centre for Toxic Compounds in the Environment, Kamenice 5, 62500 Brno, Czech Republic \\ ${ }^{2}$ Max Planck Institute for Chemistry, Multiphase Chemistry Department, Hahn-Meitner-Weg 1, 55128 Mainz, Germany
}

Correspondence: Céline Degrendele (degrendele @ recetox.muni.cz)

Received: 6 February 2018 - Discussion started: 28 March 2018

Revised: 15 August 2018 - Accepted: 22 August 2018 - Published: 6 September 2018

\begin{abstract}
This study presents multi-year monitoring data on atmospheric polybrominated diphenyl ethers (PBDEs) in central Europe. Air was sampled on a weekly basis at a background site in the central Czech Republic from 2011 to 2014 $(N=114)$. $\Sigma_{8}$ PBDEs (without BDE209) total (gas and particulate) concentrations ranged from 0.084 to $6.08 \mathrm{pg} \mathrm{m}^{-3}$, while BDE209 was at $0.05-5.01 \mathrm{pg} \mathrm{m}^{-3}$. BDE47, BDE99 and BDE183 were the major contributors to $\Sigma_{8}$ PBDEs.

Overall, the atmospheric concentrations of individual PBDEs were controlled by deposition processes, meteorological parameters and long-range atmospheric transport. Regarding gas-particle partitioning, with the exception of BDE28 (gaseous) and BDE209 (particulate), all congeners were consistently detected in both phases. Clear seasonal variations with significantly higher measured particulate fraction $\left(\theta_{\text {measured }}\right)$ in winter compared to summer was found for all PBDEs except BDE209. For example, while the average $\theta_{\text {measured }}$ of BDE47 was $0.53 \pm 0.19$ in winter, this was only $0.01 \pm 0.02$ in summer. Similarly, for BDE99, $\theta_{\text {measured }}$ was $0.89 \pm 0.13$ in winter, while it was only $0.12 \pm 0.08$ in summer. The observed gas-particle partitioning coefficient $\left(K_{\mathrm{p}}\right.$, in $\mathrm{m}^{3} \mu \mathrm{g}^{-1}$ ) was compared with three model predictions, assuming equilibrium or a steady state. None of the models could provide a satisfactory prediction of the partitioning, suggesting the need for a universally applicable model.

Statistically significant decreases of the atmospheric concentrations during 2011-2014 were found for BDE99, 100, 153 and 209. Estimated apparent atmospheric halving times for these congeners ranged from 2.8 (BDE209) to 4.8
\end{abstract}

(BDE153) years. The results suggest that photolytic debromination to lower brominated congeners may significantly influence PBDE concentration levels and patterns in the atmosphere.

\section{Introduction}

Since the late 1960s, flame retardants such as polybrominated diphenyl ethers (PBDEs) have been used in large quantities in various consumer products. Such products include plastics, textiles, electronics and cars (Besis and Samara, 2012). Three main commercial formulations have been produced: penta-BDE, octa-BDE and deca-BDE. The major congeners in each formulation were BDE47 and BDE99 for the penta mixture, BDE183 for the octa mixture and BDE209 for the deca mixture (La Guardia et al., 2006). The deca mixture has been the most widely used, accounting for approximately $83 \%$ of the total PBDE production worldwide (Besis and Samara, 2012). PBDEs are widespread contaminants as they are persistent, bioaccumulative, toxic and prone to longrange atmospheric transport (LRAT). Therefore, the use and marketing of all PBDE technical mixtures was banned in the European Union by 2008 (Besis and Samara, 2012). These mixtures have been included in the Stockholm Convention on Persistent Organic Pollutants (POPs) (UNEP, 2009).

Similar to other semi-volatile organic compounds (SOCs), once PBDEs enter the air, they partition between the gaseous 
and the particulate phase. This partitioning is controlled by the physicochemical properties of PBDEs, meteorological parameters (i.e. temperature and relative humidity) and the abundance and composition of suspended particulate matter (Lohmann and Lammel, 2004; Pankow, 1987). This partitioning will significantly affect their removal pathways (i.e. wet and dry deposition, photolysis, reaction with $\mathrm{OH}$ radicals) which are different for gases and particles (Wania et al., 1998a) and therefore their mobility and their potential for LRAT (Bidleman et al., 1986). Knowledge about this partitioning is deficient, but is crucial to predict the environmental fate of PBDEs. It is expected, due to their physicochemical properties, that lower brominated congeners such as BDE28 are mainly present in the gaseous phase, while higher brominated congeners such as BDE209 are > 99\% present in the particulate phase (Harner and Shoeib, 2002; ter Schure et al., 2004). However, results from individual studies are contradictory on a global scale. For example, some studies have found that the particulate fraction of PBDEs was small for most PBDEs investigated (e.g. $<20 \%$, Iacovidou et al., 2009). But other studies reported that the particulate fraction significantly increased with increasing degree of bromination for the same temperature (Davie-Martin et al., 2016; Möller et al., 2011; Strandberg et al., 2001; Su et al., 2009). Recently, $\mathrm{Li}$ and co-workers developed a new gas-particle partitioning theoretical model for PBDEs based on the assumption that the equilibrium between both phases is not reached due to disturbances caused by wet and dry deposition ( $\mathrm{Li}$ et al., 2015), but the universal applicability of this model still remains to be shown (Besis et al., 2017).

About a decade after the European ban on PBDEs, it is still unclear whether global atmospheric concentrations are significantly declining or not. This is due to the limited amount of ambient air monitoring data, particularly in central Europe. In order to understand whether primary or secondary sources are controlling the atmospheric concentrations of PBDEs, and hence to guide future control strategies, more data are needed to fill this gap.

The aim of this study is to provide multi-year monitoring data on atmospheric PBDEs at a background site in central Europe and to assess whether the PBDE atmospheric concentrations are significantly decreasing or not in a time span of 4 years. In particular, the seasonal and semi-long-term variations as well as the gas-particle partitioning of PBDEs were investigated.

\section{Methodology}

\subsection{Air sampling}

Air was sampled at the Košetice Observatory $\left(49^{\circ} 34^{\prime} 24^{\prime \prime}\right.$ N, $15^{\circ} 04^{\prime} 49^{\prime \prime} \mathrm{E}$ ), which is an established background site of the European Monitoring and Evaluation Programme (EMEP) network (Holoubek et al., 2007). The site is located, in an agricultural region, centrally in the Czech Republic. From January 2011 to December 2014, a high-volume air sampler (Digitel DH77 with $\mathrm{PM}_{10}$ pre-separator) was used to collect weekly air samples. The sampler addressed the inhalable size fraction, $\mathrm{PM}_{10}$. PBDEs are mostly sorbed to fine and sub-micrometre-sized particles (Okonski et al., 2014; Besis et al., 2017). The sample volume was $5264 \mathrm{~m}^{3}$ on average $\left(\approx 31.3 \mathrm{~m}^{3} \mathrm{~h}^{-1}, 7\right.$-day sampling duration). Particles were collected on quartz fiber filters (QFFs, QMA, $150 \mathrm{~mm}$, Whatman, UK) and gas-phase chemicals on polyurethane foam (PUF, two in series, T3037, $110 \times$ $50 \mathrm{~mm}, 0.030 \mathrm{~g} \mathrm{~cm}^{-3}$, Molitan a.s., Czech Republic). PUFs were pre-cleaned via Soxhlet extraction with acetone and dichloromethane for $8 \mathrm{~h}$ each. PBDE analysis was performed on all weekly samples in 2011 and on half of the available weekly samples for the remaining years (Table S1 in the Supplement). Several problems (e.g. sudden change in the flow rate, electrical power shutdown) occurred during the collection, and the corresponding 13 samples were discarded without further analysis (Table S1). After sampling, all filters and PUFs were wrapped in aluminium foil, sealed in plastic bags and stored at $-18^{\circ} \mathrm{C}$ until analysis.

\subsection{Sample preparation and analysis}

Samples were extracted with dichloromethane by means of an automated extraction system (Büchi B-811, Switzerland). Mass-labelled internal standards $\left({ }^{13} \mathrm{C}\right.$ labelled BDE28, BDE47, BDE99, BDE100, BDE153, BDE154, BDE183 and BDE209, Wellington Laboratories, Canada, and LGC, UK) were added to each sample prior to extraction. The clean-up and fractionation differed between samples collected prior to and after 2013. Samples from 2011 to 2012 were prepared as follows: the concentrated extracts underwent clean-up using a sulfuric acid $\left(\mathrm{H}_{2} \mathrm{SO}_{4}\right)$ modified silica column, eluted with $40 \mathrm{~mL} \mathrm{DCM} / n$-hexane mixture $(1: 1)$. Fractionation was achieved in a disposable Pasteur pipette microcolumn containing (from bottom to top) $50 \mathrm{mg}$ silica, $70 \mathrm{mg}$ charcoal / silica ( $1: 40)$ and $50 \mathrm{mg}$ of silica (Darco G60 charcoal). The column was prewashed with $5 \mathrm{~mL}$ of toluene, followed by $5 \mathrm{~mL}$ of DCM / cyclohexane mixture (30\%), then the sample was loaded and eluted with $9 \mathrm{~mL} \mathrm{DCM} /$ cyclohexane mixture $(30 \%)$ in fraction 1 and $40 \mathrm{~mL}$ of toluene in fraction 2. The first fraction was used for PBDE analysis and was concentrated to the final volume of $50 \mu \mathrm{L}$ and then transferred into an insert in a vial. Samples from 2013 to 2014 were prepared as follows: the clean-up column was achieved using a multi-layer silica column ( $\mathrm{KOH}$ silica, $\mathrm{H}_{2} \mathrm{SO}_{4}$ silica, $\mathrm{Na}_{2} \mathrm{SO}_{4}$, prewashed with $n$-hexane), and analytes were eluted with $120 \mathrm{~mL}$ of $n$-hexane. Fractionation was performed on a carbon column packed with $50 \mathrm{mg}$ of AX-21 active carbon dispersed on $1 \mathrm{~g}$ of Celite 545. After elution with $18 \mathrm{~mL}$ of a mixture of cyclohexane:DCM : methanol $(2: 2: 1, v / v)$ (fraction 1, part of ortho PBDEs) and $6.5 \mathrm{~mL}$ of toluene (fraction 2 non-ortho PBDEs), fraction 3, eluted with 
$80 \mathrm{~mL}$ of toluene applied on a column with reverse flow, was collected. After instrumental analyses of other organic compounds, fraction 1 and 2 were combined, transferred to an insert in a vial, spiked with the recovery standard $\left({ }^{13} \mathrm{C}\right.$ BDE77 and 138) and analysed for PBDEs.

Nine PBDEs (BDE28, BDE47, BDE85, BDE99, BDE100, BDE153, BDE154, BDE183 and BDE209) were analysed using high resolution on an Agilent 7890A Gas Chromatograph (Agilent, USA) equipped with a $15 \mathrm{~m} \times 0.25 \mathrm{~mm} \times 0.10 \mu \mathrm{m}$ DB-5 column (Agilent, J\&W, USA) (samples from 2011) or a $15 \mathrm{~m} \times 0.25 \mathrm{~mm} \times 0.10 \mu \mathrm{m}$ RTX-1614 column (Restek, USA) (samples from 2012 onwards) coupled to an AutoSpec Premier Mass Spectrometer (MS; Waters, Micromass, UK). The MS was operated in EI+ at a resolution of $>10000$. The temperature programme was $80^{\circ} \mathrm{C}$ ( 1 min hold $)$, then $20^{\circ} \mathrm{C} \mathrm{min}^{-1}$ to $250{ }^{\circ} \mathrm{C}$, followed by $1.5^{\circ} \mathrm{C} \mathrm{min}{ }^{-1}$ to $260^{\circ} \mathrm{C}$ and $25^{\circ} \mathrm{C} \mathrm{min}^{-1}$ to $320^{\circ} \mathrm{C}(4.5 \mathrm{~min}$ hold). The injection volume was $3 \mu \mathrm{L}$ in splitless mode at $280{ }^{\circ} \mathrm{C}$, with $\mathrm{He}$ used as a carrier gas at a constant flow of $1 \mathrm{~mL} \mathrm{~min}{ }^{-1}$. The instrumental limits of quantification (iLOQs) were determined from calibration curves or from individual sample chromatograms corresponding to a signal-to-noise ratio $>9$.

\subsection{Quality assurance and quality control}

A total of 11 field blanks and 11 laboratory blanks were analysed as per samples. Except for BDE209, blank levels of individual analytes were below detection or otherwise low (on average $<5 \%$ of sample mass for detected compounds), suggesting minor contamination during sampling, transport and analysis. In the case of BDE209, high blank levels were found in some cases (on average $10.1 \%$ and $35.1 \%$ of sample mass for QFFs and PUF, respectively). The higher blanks are probably caused by elevated background concentrations of BDE209; this may be related to the microabrasion of particles from plastic materials containing BDE209 (Webster et al., 2009). The PBDE concentrations presented here were blank-corrected by subtracting the average of the field blanks on an annual basis, separately for QFFs and PUFs. The PBDEs were quantified using isotope dilution and thus recovery-adjusted. Mean PBDE recoveries ( \pm standard deviation) ranged from $60.9 \%$ for BDE183 to $149.9 \%$ for BDE209, with an average value of $92.7 \%$. Limits of quantifications (LOQs) were determined as the maximum of the iLOQs and the average of the field blanks plus 3 times their standard deviations. LOQs ranged from $2.09 \times 10^{-5}$ to $1.04 \mathrm{pg} \mathrm{m}^{-3}$ (Table S2). The different methods of sample preparation and/or column used has a minor effect on the overall quality of the data $(<12 \%$; Tables S3 and S4). Therefore, the data obtained are directly comparable and suitable to derive long-term trends.

\subsection{Modelling of gas-particle partitioning}

Partitioning of organic compounds such as PBDEs between the gas and particle phases is often described using the gasparticle partition coefficient, $K_{\mathrm{p}}$ (in $\mathrm{m}^{3} \mu \mathrm{g}^{-1}$ ), defined by Harner and Bidleman (1998a) as

$K_{\mathrm{p}}=\left(C_{\mathrm{p}} / C_{\mathrm{TSP}}\right) / C_{\mathrm{g}}$,

where $C_{\mathrm{p}}$ and $C_{\mathrm{g}}$ are the concentrations of individual PBDEs (in $\mathrm{pg} \mathrm{m}^{-3}$ ) in the particulate and gaseous phases, respectively, and $C_{\text {TSP }}$ is the concentration of the total suspended particles (TSP) in the air (in $\mu \mathrm{g} \mathrm{m}^{-3}$ ).

Accurate knowledge of $K_{\mathrm{p}}$ is crucial for modelling the fate of PBDEs in the environment. In this study, we compared the experimental $K_{\mathrm{p}}$ values with those determined by three predictive models. For comparison, we only considered cases in which individual PBDEs were detected in both the gas and the particle phase. The first approach, also known as the $K_{\mathrm{OA}}$ model, predicts $K_{\mathrm{p}}$ based on the octanol-air partitioning coefficient $\left(K_{\mathrm{OA}}\right)$. It implicitly assumes that equilibrium has been reached between the two phases and that absorption into particulate organic matter (OM) of the particles determines the distribution process, while other types of molecular interaction (i.e. adsorption to the unspecific surface, to minerals or soot) are negligible (Harner and Bidleman, 1998a). Then, assuming that the activity coefficient of the absorbing compound and its molecular weight is the same in octanol and organic matter, $K_{\mathrm{p}}$ can be defined as (Harner and Bidleman, 1998b)

$\log K_{\mathrm{p}_{\mathrm{e}, \mathrm{abs}}}=\log K_{\mathrm{OA}}+\log f_{\mathrm{OM}}-11.91$,

where the subscript e,abs in $K_{\mathrm{p}}$ highlights the equilibrium assumption of this approach and the fact that it considers only absorptive contributions, and $f_{\mathrm{OM}}$ is the fraction of organic matter phase of particles.

The second approach used is the steady-state model proposed by Li et al. (2015) in which $K_{\mathrm{p}}$ is defined as

$\log K_{\mathrm{p}_{\mathrm{s}, \mathrm{ss}}}=\log K_{\mathrm{p}_{\mathrm{e}, \mathrm{abs}}}+\log \alpha$

where $\log \alpha$ represents the non-equilibrium term due to disturbances from wet and dry deposition of particles and is defined as

$\log \alpha=-\log (1+G / C)$

where

$C=5$ and $G=2.09 \times 10^{-10} f_{\mathrm{OM}} K_{\mathrm{OA}}$.

Finally, the last approach is based on a quantitative structure-property relationship (QSPR) model recently proposed by Wei et al. (2017). To fit this regression model, several properties were calculated quantum-mechanically for each PBDE molecule in the gas phase. The regression fitting 
was done for a dataset in which temperature varied between 10 and $32^{\circ} \mathrm{C}$. This model also implicitly assumes that equilibrium exists between PBDEs in the gas and particle phase. In this approach, $\log K_{\mathrm{p}}$ is defined as

$$
\begin{aligned}
& \log K_{\mathrm{p}_{\mathrm{e}, \mathrm{QSPR}}}= \\
& 0.026 V-0.030 T-0.858 q \mathrm{C}^{-}+3.864 q \mathrm{H}^{+}+0.002
\end{aligned}
$$

where $V$ is the molecular volume, $T$ is the ambient temperature, $q \mathrm{C}^{-}$is the most negative charge on a carbon atom and $q \mathrm{H}^{+}$is the most positive charge on a hydrogen atom (Wei et al., 2017). These were Mulliken charges calculated with density functional theory at the B3LYP/6-31G(d,p) level.

Equations (1)-(6) can be used to predict the particulate fractions $\left(\theta_{\mathrm{pr}}\right)$ using

$\theta_{\mathrm{pr}}=K_{\mathrm{p}} C_{\mathrm{TSP}} /\left(1+K_{\mathrm{p}} C_{\mathrm{TSP}}\right)$.

Given that most PBDEs are sorbed to fine particles (Okonski et al., 2014), the concentration of particles smaller than $10 \mu \mathrm{m}\left(\mathrm{PM}_{10}\right)$ instead of $C_{\mathrm{TSP}}$ and the measured $f_{\mathrm{OM}}$ at this site were used (data provided by the Czech Hydrometeorological Institute, http://www.chmi.cz, last access: 10 January 2018). The $f_{\mathrm{OM}}$ values were calculated from the atmospheric concentrations of organic carbon (available in $\mu \mathrm{g} \mathrm{m}^{-3}$; a conversion factor from organic carbon to $\mathrm{OM}$ of 1.8 was used; El-Zanan et al., 2005), which were determined every sixth day. The corresponding weekly averages were used and ranged from 0.07 to 0.98 , with an average value of $0.39 \pm 0.19$. The temperature dependence of $K_{\mathrm{OA}}$ for all PBDEs, except BDE209, was determined from published relationships, based on direct measurements (Harner and Shoeib, 2002).

\subsection{Meteorological data and air mass origin}

Continuous meteorological data, including $2 \mathrm{~m}$ above ground level (a.g.l.) temperature, relative humidity and $2 \mathrm{~m}$ a.g.l. wind speed and direction, were provided by the observatory (Czech Hydrometeorological Institute).

The influence of LRAT was assessed by evaluating the backward trajectories of specific samples. The Lagrangian particle dispersion model FLEXPART (Stohl et al., 2005) was used to identify air mass origins of the 10 samples showing the highest and the lowest PBDE concentrations from our dataset. The meteorological data $\left(0.5^{\circ}\right.$ and $3 \mathrm{~h}$ resolution, 91/137 vertical levels) were retrieved from the ECMWF database (http://www.ecmwf.int, last access: 10 January 2018). For every weekly sample investigated, 100000 particles were released between 0 and $200 \mathrm{~m}$ a.g.l. and were followed 5 days backward in time. Additional details can be found elsewhere (Mulder et al., 2015).

\section{Results}

\subsection{Breakthrough and sampling artefacts}

Breakthrough is an issue of concern as relatively high sample volumes (i.e. $>1000 \mathrm{~m}^{3}$ ) are usually used to quantify trace contaminants such as PBDEs. Breakthrough of gas-phase PBDEs was evaluated by separately quantifying each of the two PUFs placed in series for all the weekly air samples collected in $2012\left(N=26\right.$, sampled volume $\left.=4015-5864 \mathrm{~m}^{3}\right)$. This covered a large range of meteorological conditions and the results are considered applicable to the other years. The results of the breakthrough experiments are summarized in Table S5 and Fig. S1. On average, less than $6 \%$ of individual PBDEs was found on the lower PUF, except for BDE183 and BDE209 (Table S5). In the cases of BDE183 and BDE209, 24.6 and $82.0 \%$ on average were found on the lower PUF, respectively. Given that these compounds are not volatile (i.e. vapour pressure at $25^{\circ} \mathrm{C}$ of $3.30 \times 10^{-6}$ and $1.43 \times 10^{-8} \mathrm{~Pa}$, respectively; Yue and $\mathrm{Li}, 2013$ ), it is unlikely that the high fractions found on the lower PUFs would be caused by breakthrough. Instead, this could have been caused by sampling artefacts or by contamination. Blow-off, which is the loss of SOCs from the filter by evaporation, can disproportionately increase the SOC PUF masses (Melymuk et al., 2014). This effect has already been reported for PBDEs (Allen et al., 2007; Besis and Samara, 2012). However, despite the large volume collected which could enhance this sampling artefact, we consider it unlikely. This process should affect all PBDEs in the same manner, but in many cases, only BDE209 was found only on the lower PUF (Table S5). Similarly, a physical breakthrough of fine particles is possible, but this could not explain the fact that $100 \%$ of BDE183 or BDE209 was found on the lower PUF. We suggest that the unexpected amounts found on the lower PUFs for these two congeners are the result of contamination from sampling or sample preparation. Indeed, it is unclear whether some flame retardants (likely the deca mixture) have been used in some electronic and plastic parts present within the air sampler or even within the PUF itself, which was characterized by high field blank levels for BDE209 (see Sect. 2.3). Contamination within the laboratory (i.e. microabrasion of particles from plastic material containing BDE209) is also possible. We should keep in mind that the analysis of BDE209 is more challenging (Law et al., 2008).

Given that Bidleman and Tysklind (2018) demonstrated that when less than $33 \%$ is found on the lower PUF plug, the collected gaseous mass fractions should be larger than $90 \%$, we consider the current sampling configuration and sample preparation to be efficient for trapping all gas-phase PBDE congeners addressed, with the exception of BDE209. 


\subsection{PBDE concentration levels}

Except for BDE85, all congeners were detected in $>89 \%$ of the samples (Table S6); this highlights their persistency in the environment. In this study, the total (gas and particles) concentrations of $\Sigma_{8}$ PBDEs (all congeners except BDE209) ranged from 0.0843 to $6.08 \mathrm{pg} \mathrm{m}^{-3}$, with an average value of $0.524 \mathrm{pg} \mathrm{m}^{-3}$. BDE209 had a lower average concentration of $0.457 \mathrm{pg} \mathrm{m}^{-3}$ (ranging from < LOQ to $4.72 \mathrm{pg} \mathrm{m}^{-3}$ ) (Table S6). The PBDE concentrations reported here were similar to those observed for other European background or remote sites (Besis et al., 2016, 2017; Besis and Samara, 2012; Degrendele et al., 2016; Iacovidou et al., 2009), which are usually lower than $5 \mathrm{pg} \mathrm{m}^{-3}$ (Lee et al., 2004). These background levels are lower than those previously reported for urban sites (Moeckel et al., 2010; Okonski et al., 2014; Salamova and Hites, 2011).

Besides BDE209, which on average contributed to $46.6 \%$ of all PBDEs measured, BDE47, 99 and 183 showed the highest concentrations. On average these accounted for $32.5 \%, 25.2 \%$ and $14.6 \%$ of $\Sigma_{8}$ PBDEs, respectively. As observed in Fig. S2, the PBDE profile differed between the two atmospheric phases, with the light congeners having a larger contribution to $\Sigma_{8}$ PBDEs in the gaseous phase compared to the particulate phase. This PBDE profile, with BDE209 being the prevalent congener, is typical of European environments (Besis et al., 2017; Besis and Samara, 2012; Okonski et al., 2014). This contrasts with North America, where BDE47 and BDE99 usually dominate the BDE levels (Besis and Samara, 2012; Liu et al., 2016; Ma et al., 2013; Shunthirasingham et al., 2018). Given that the technical deca mixture represents $83 \%$ of the global PBDE market (in 2001; Besis and Samara, 2012), these distributions suggest that either lower congeners are more prone to volatilization from products or from other environmental media compared to the higher brominated congeners or that photolytic degradation of BDE209 to lower brominated BDEs is occurring (Luo et al., 2014). Indeed, an increase of lower brominated congeners (hexa through nona) was observed under photolysis of BDE209 in solvents, sediments, soils and sands (Eriksson et al., 2004; Söderström et al., 2004). However, photolysis is not specific to BDE209, but relevant for all congeners, such as BDE99 (formation of BDE47; Fang et al., 2008; SanchezPrado et al., 2005).

\subsection{Gas-particle partitioning in air samples}

Results of PBDE gas-particle partitioning from individual studies at a global scale are contradictory. For example, some studies have found that most PBDEs have small particulate fractions (Besis et al., 2017; Iacovidou et al., 2009; Mandalakis et al., 2009; Mulder et al., 2015), while other studies have found that, for a specific temperature, the particulate fraction significantly increased with increasing degree of bromination (Chen et al., 2006; Davie-Martin et al., 2016;
Möller et al., 2011; Strandberg et al., 2001). In this study, with the exception of BDE28 and BDE209, which were detected in about half of the samples only in one phase ( $\mathrm{Ta}$ ble S6), the remaining congeners were significantly detected in both phases. The particulate fraction $\left(\theta_{\text {measured }}\right)$ significantly increased with the degree of bromination (Fig. S3). For example, for BDE28, the average $\theta_{\text {measured }}$ was 0.11 , while it was 0.24 for BDE47, 0.49 for BDE99, 0.62 for BDE154 and 0.72 for BDE183 (Fig. S3). This is consistent with previous studies (Davie-Martin et al., 2016; Strandberg et al., 2001). However, it is important to note that large seasonal variations were observed (Figs. 1 and S3). Indeed, while $\theta_{\text {measured }}$ of BDE47 was on average $0.53 \pm 0.19$ in winter, this was only $0.01 \pm 0.02$ in summer. Similarly, for BDE99, $\theta_{\text {measured }}$ was $0.89 \pm 0.13$ and $0.12 \pm 0.08$ in winter and summer, respectively. Statistically significant $(p<0.05)$ correlations between $\theta_{\text {measured }}$ or $\log K_{\mathrm{p}}$ and $1 / T$ were found for all individual congeners investigated, except BDE209 (Table S7). The large seasonal differences in the gas-particle partitioning of PBDEs have been previously reported from a rural site in the North American Great Lakes area, where the differences in the ambient temperatures were similar to this study, about $30^{\circ} \mathrm{C}$ (Su et al., 2009). Less seasonal difference in gas-particle partitioning was found in the Arctic or in Greece, where the temperature range was lower than $20^{\circ} \mathrm{C}$ (Besis et al., 2016; Davie-Martin et al., 2016).

In the case of BDE209, the reported particulate fractions may be associated with uncertainties (see Sect. 3.1). This congener was found in about half of the samples only in the particulate phase, and the average $\theta_{\text {measured }}$ was 0.72 . The influence of ambient temperature on $\theta_{\text {measured }}$ or $\log K_{\mathrm{p}}$ of BDE209 was different than for the other congeners (Table S7). Previously reported particulate fractions for this compound ranged between extreme values (i.e. $\theta=0-1$ ) (Cetin and Odabasi, 2007), though some studies reported it to mainly be in the particulate phase (Cetin and Odabasi, 2008; Li et al., 2016; Ma et al., 2013; Strandberg et al., 2001; Su et al., 2009), and others mainly in the gas phase (Agrell et al., 2004; and references within $\mathrm{Li}$ et al., 2016). Li et al. (2016) recently reported on BDE209 levels found on a global scale and also noted the large range of particulate fractions found.

\subsection{Modelling of gas-particle partitioning}

BDE209 was not considered in the different modelling approaches for two main reasons. Firstly, higher uncertainties are associated with the measured particulate fractions for this compound (see Sect. 3.1). Secondly, two of the tested models are based on $K_{\mathrm{OA}}$, and the temperature dependence of this parameter is not available (never determined experimentally).

As presented in Figs. 2 and S4, none of the three model approaches successfully predicted $K_{\mathrm{p}}$ or $\theta$ for all individual PBDEs considered, which is also the case when considering only winter or summer samples (Fig. S5). The $K_{\mathrm{OA}}$ model 

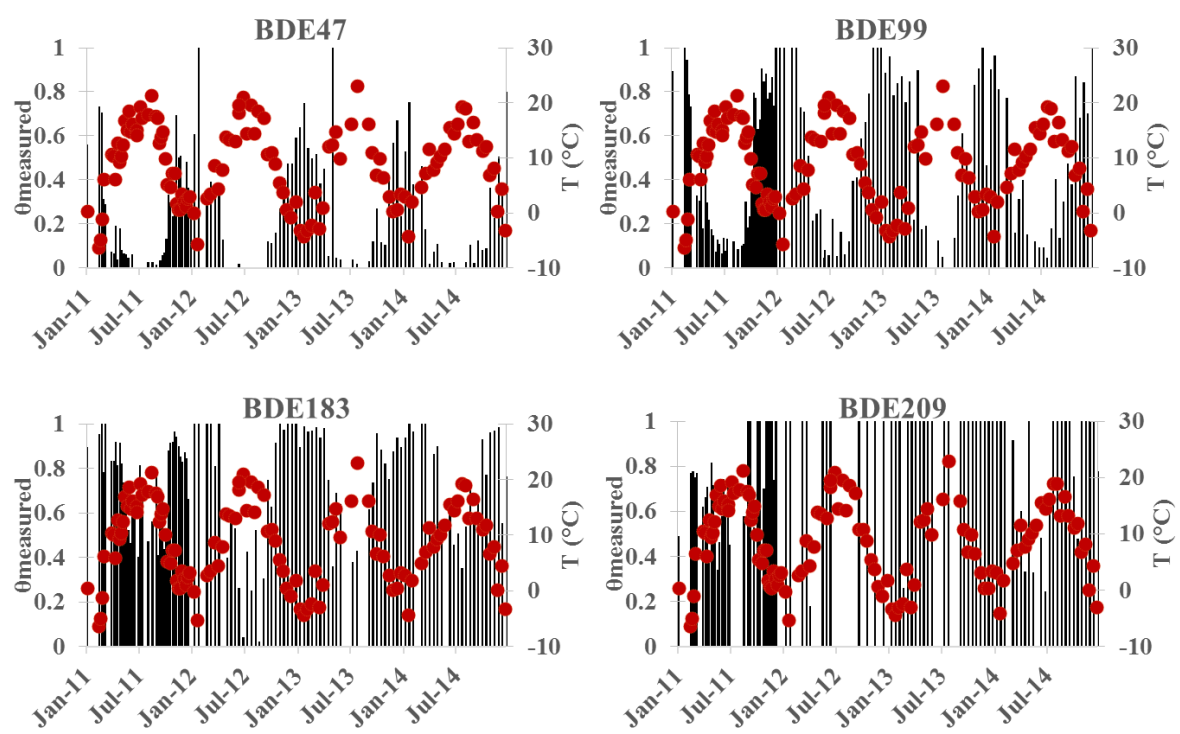

Figure 1. Time series of particulate fraction $\left(\theta_{\text {measured }}\right)$ of selected PBDE congeners. Red dots represent the average temperature for each sample.

generally captured the overall trend regarding temporal variations of gas-particle partitioning (similar slope as the 1:1 line in Fig. 2) but, with the exception of BDE28, consistently overestimated $K_{\mathrm{p}}$ by $1-2$ orders of magnitude. This results in an important overestimation of the particulate fraction as this model predicted that the majority of PBDEs would be mostly present in the particulate phase $\left(\theta_{\text {predicted }}\right.$ often $>0.9$, Fig. S4). This is in clear disagreement with our observations. Only for BDE28 did this model provide satisfactory results. This overestimation of $K_{\mathrm{p}}$ by the $K_{\mathrm{OA}}$ model has also been previously reported for different sites in the Mediterranean and China (Besis et al., 2017; Cetin and Odabasi, 2008; Chen et al., 2006).

Similarly to the $K_{\mathrm{OA}}$ model, the estimations provided by the steady-state approach were only acceptable for BDE28. For the other congeners, this model consistently over- and under-predicted $K_{\mathrm{p}}$ by 1-2 orders of magnitude depending on the compound and season investigated. This model tends to predict that these PBDEs will be within the maximum partition domain (Li et al., 2015) for which $\log K_{\mathrm{p}}$ is constant with a value of -1.53 , regardless of the ambient temperature (Fig. 2). This model predicted that the maximum particulate mass fraction for all PBDEs would be $\approx 0.6$, given the conditions at the sampling site, which is in disagreement with the observed seasonal variations of this study (discussed above). The only other study testing this model to atmospheric PBDE data did not find an acceptable performance for all PBDEs investigated, although, for BDE209 it predicted a better performance than the $K_{\mathrm{OA}}$ model (Besis et al., 2017).

The QSPR model generally tends to underestimate $K_{\mathrm{p}}$ for all compounds studied, except for BDE153 and 183 for which satisfactory predictions were found (Fig. 2). For exam- ple, for BDE28, this model predicts that at most $7 \%$ will be present on particles, while in reality, cases with $>20 \%$ on particles were often found for cold temperatures (Fig. S4). We note that this regression model has been fitted to data within a limited temperature range $\left(10-32^{\circ} \mathrm{C}\right)$; therefore attempts to extrapolate outside of this range (in this study, the average weekly temperatures were -6.4 to $23.0^{\circ} \mathrm{C}$ ) may not be appropriate. However, even within this range, a severe underestimation is seen. We suggest that the complex molecular interactions involved in the partitioning processes cannot be fully captured based on a limited selection of gas-phase atomic charges only. For a truly universal regression model, calculations of the interactions between PBDEs and different particle matrices would be required.

As we have seen, none of the models are able to predict the partitioning of PBDEs in a satisfactory way. Though, while considering the average conditions for this study, the overall tendency of predicting $K_{\mathrm{p}}$ or $\theta$ using the steady-state model or the QSPR model was higher than from the $K_{\mathrm{OA}}$ model (Fig. S6), we do not recommend the use of these models given that the very pronounced seasonal variations observed were not captured. Moreover, we would like to reiterate that though in most cases, these two models predicted $K_{\mathrm{p}}$ within 1 order of magnitude of the observed value, this can still result in highly inaccurate values of $\theta$ (Fig. S7). Therefore, these models are not ideal when phase-specific removal processes such as the wet scavenging of particles (see Sect. 3.3) are to be estimated.

Addressing unrealistic implicit assumptions of these models is obviously crucial for the understanding of these discrepancies. 

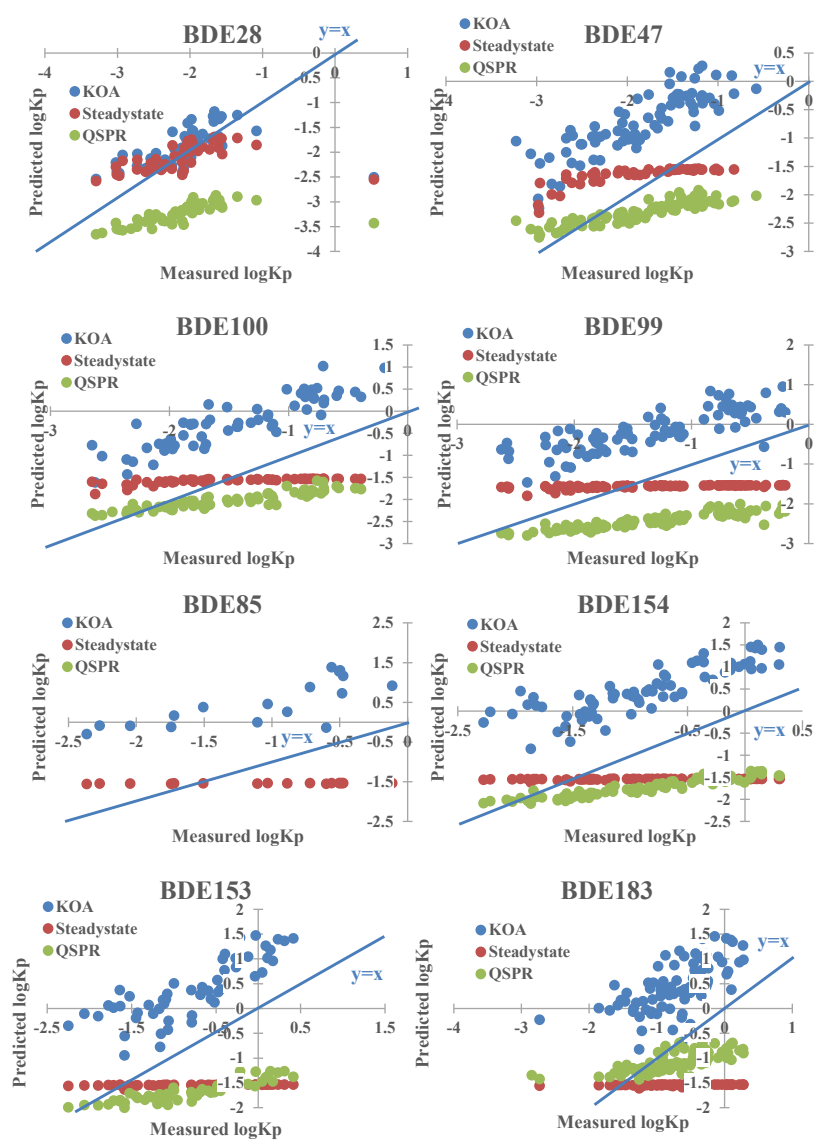

Figure 2. Comparison of measured and predicted $\log K_{\mathrm{p}}$ of individual PBDEs. The blue lines represent the $1: 1$ line. No data from the QSPR model were available for BDE85.

The $K_{\mathrm{OA}}$ model represents absorption in octanol and therefore does not exactly reflect the true process of adsorption on aerosols (a process that must precede any absorption). We highlight a study by Ding et al. (2014) which investigated the adsorption of different congeners on graphene (a structure that on a molecular level has similarities to black carbon). It was found that, in addition to the number of bromine atoms, the adsorption energy was also affected by the 3-D structure of the PBDE congener. Specifically, steric interactions between bromine atoms in the ortho position (relative to the oxygen-substituted carbon atom) appear to be important. This effect is best illustrated by congeners BDE153 and BDE154, both of which have the same number of bromine atoms. However, BDE154 has three $\mathrm{Br}$ atoms in the ortho position; this meant the congener adopted a twisted structure and adsorbed more weakly onto the graphene surface. $\mathrm{BDE} 153$, on the other hand, with only two $\mathrm{Br}$ atoms in the ortho position, can adopt a planar structure and adsorb more strongly. The consequences of this effect are observed in our results (Fig. S8). We also note similar behaviour between BDE99 and BDE100; it appears that congeners with more $\mathrm{Br}$ atoms in the ortho position tend to have smaller partic-

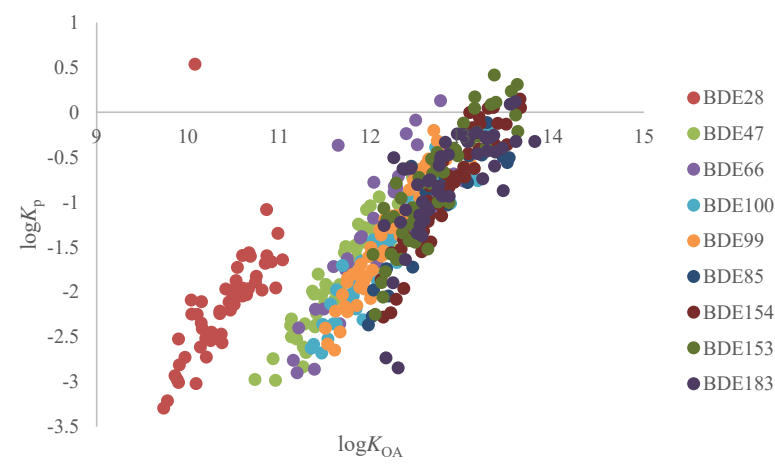

Figure 3. Influence of $\log K_{\mathrm{OA}}$ on measured $\log K_{\mathrm{p}}$ for individual PBDEs.

ulate fractions when compared with other congeners of the same mass. Such effects are not captured by using $K_{\mathrm{OA}}$ alone as a predictor (octanol, having more degrees of freedom, can better accommodate twisted structures). We speculate these effects could influence the ability of specific BDEs to both adsorb onto and diffuse within the bulk condensed phases of PM. Furthermore, octanol is not necessarily the perfect surrogate to describe absorption in particulate $\mathrm{OM}$; better results for the prediction of $\theta$ of polycyclic aromatic hydrocarbons (PAHs) were achieved when absorption in octanol was replaced by absorption in two particulate OM phases, using dimethyl sulfoxide and polyurethane, respectively, as the surrogates in a polyparameter linear free energy relationships model (Shahpoury et al., 2016).

Regarding the steady-state approach, our results tend to support the conceptual idea behind the model, i.e. that equilibrium between the gaseous and particulate phases is not reached beyond a certain $\log K_{\mathrm{OA}}(11.5$ suggested by Li et al., 2015). Indeed, we observed a distinctly different behaviour in the gas-particle partitioning for PBDEs with $\log K_{\mathrm{OA}}<11$ within the environmental conditions observed (i.e. BDE28) and for all other PBDEs with $\log K_{\mathrm{OA}}>11$ (Fig. 3). Taking into account that the steady-state model considers BDE28 to be within equilibrium ( $\mathrm{Li}$ et al., 2015) and that the equilibrium $K_{\mathrm{OA}}$ model provided satisfactory results only for BDE28, our results tend to suggest that other PBDEs are not within $K_{\mathrm{OA}}$-predicted equilibrium but instead a different equilibrium or steady state. However, it is evident from Fig. 2 that the considerations taken within the steady-state model are inadequate to correctly characterize the gas-particle partitioning of PBDEs. Li et al. (2015) suggested that this deviation from equilibrium is due to the influence of wet and dry deposition. However, the term describing this influence in Eq. (4) does not consider important characteristics of the site such as meteorological conditions (e.g. precipitation rate, temperature) or aerosol properties (e.g. mass size distribution, PM composition). Though we recognize that wet and dry deposition may increase the relative presence of PBDEs in the gas phase, we do not consider this to be the major 
mechanism resulting in the steady state of most PBDEs for two reasons.

Firstly, we note that because rain scavenging is more efficient for particles than gases (Wania et al., 1998a), samples associated with more intense precipitation are likely to have a lower particulate fraction. This overall trend was observed in this study as statistically significant $(p<0.05)$ correlations between $\theta_{\text {measured }}$ and the precipitation rate were found for all PBDEs (Table S8). However, the sample with the highest precipitation rate (i.e. $112 \mathrm{~mm}$ ) had a higher particulate fractions than the following sample which had almost no rain (i.e. $0.4 \mathrm{~mm}$ ), and this was also observed for other subsequent samples. Therefore, we do not consider wet deposition (nor dry deposition) to be the factor governing the equilibrium (or absence it) of PBDEs. Secondly, this concept should not be exclusive to PBDEs but should also be valid for other SOCs such as benzo(a)pyrene, a high molecular weight PAH with a $\log K_{\mathrm{OA}}$ of 11.6 at $25^{\circ} \mathrm{C}$. This compound is generally found only in the particulate phase (Shahpoury et al., 2015), with only a limited amount in the gaseous phase. It is therefore unclear why disturbances due to wet and dry deposition should be more pronounced for PBDEs than PAHs. As previously suggested by Cetin and Odabasi, we consider that the higher presence of PBDEs in the gas phase (compared to that expected based on $K_{\mathrm{OA}}$ ) is due to their departure from equilibrium partitioning and that the relaxation to equilibrium is slower for compounds with higher $\log K_{\mathrm{OA}}$ (Cetin and Odabasi, 2008).

To look more widely at processes that could cause departure from the $K_{\mathrm{OA}}$-predicted equilibrium, we should also recognize that there are other factors, beyond the thermodynamic stability of PBDEs in the particle phase, which could also influence the particulate fraction. We cannot assume the lifetime of PBDEs in the particle phase is identical to the lifetime in the gas phase. If the difference between these two lifetimes becomes significant, we would expect a shift from the $K_{\mathrm{OA}}$-predicted equilibrium. Li et al. (2015) considered this idea in terms of dry and wet deposition. We suggest there may also be chemical factors that influence this process. We note a study by Raff and Hites (2007), in which gas-phase photolysis rate constants are estimated for different BDE congeners. Even amongst congeners with the same number of bromine atoms, significant differences exist in gas-phase lifetimes, for example between BDE99 (4h) and BDE100 (54h).

\subsection{Factors affecting the inter-sample variations}

Different parameters can influence the inter-sample variation of PBDE atmospheric concentrations. These factors include advection from urban and industrial sources, the efficiency of removal processes (degradation and deposition) and the meteorological conditions (e.g. temperature, boundary layer height, precipitation). The results of the Spearman correlation analysis between the gaseous, particulate and total con- centrations of individual PBDEs and different meteorological parameters are shown in Table S9.

No or low influence of wind speed and wind direction on the PBDE concentrations was observed, consistent with previous studies (Besis et al., 2015; Cetin and Odabasi, 2008) but also more generally consistent for POPs (Hafner and Hites, 2005). As observed elsewhere (Dien et al., 2015), the particulate concentrations of high brominated PBDEs (i.e. 99, 100, 153, 154, 183 and 209) were negatively correlated with the precipitation rate. This confirms the significant washout of congeners' partitioning mostly to the particulate phase compared to those in the gas phase (Venier and Hites, 2008), a general trend for lipophilic organic compounds (Ligocki et al., 1985; Shahpoury et al., 2015). The atmospheric boundary layer (ABL) height shows strong correlations with the particulate concentrations of all PBDEs except BDE85, in agreement with a previous study (Dien et al., 2017). The ABL height was also shown to be a primary driver of PBDE concentration's diel variability (Moeckel et al., 2010).

An examination of the temperature dependence of the PBDE gaseous concentrations using the Clausius-Clapeyron equation (see Supplement) was done and results are presented in Table S10. Significant correlations were found between the natural logarithm of partial pressure versus the inverse of ambient temperature for all PBDEs, except BDE28 and BDE209. This suggests that the gas-phase concentrations of these two congeners are not controlled by temperaturedependent sources. This lack of temperature dependence has been previously attributed to long-range atmospheric transport (Hoff et al., 1998; Wania et al., 1998b). However, at least for BDE28, we suggest that the photolytic debromination of higher brominated congeners (Bezares-Cruz et al., 2004; Wei et al., 2013) may also play a role. In the case of the remaining congeners, the strong influence of ambient temperature on the gaseous concentrations of PBDEs, characterized by the high slopes in Table S10, has often been interpreted by previous studies (Cetin and Odabasi, 2008; DavieMartin et al., 2016) as a demonstration that PBDE gaseous concentrations are controlled by revolatilization from surfaces (soil or water). However, given the large influence of ambient temperature on $\theta_{\text {measured }}$ (see Sect. 3.4), it is uncertain that the gaseous concentrations of PBDEs are controlled by air-surface exchange rather than by revolatilization from the particles. Therefore, we would suggest focusing the interpretation of the Clausius-Clapeyron equation only on those substances which are mainly in the gas phase (i.e. $\theta_{\text {measured }}<0.2$ ), regardless of the ambient temperature. Following this, we can only conclude from the present study that the gaseous concentrations of BDE28 were not controlled by air-surface exchange.

On the other hand, the particulate concentrations of all individual PBDEs were significantly $(p<0.05)$ higher at colder temperatures (Fig. S9), as found for semi-volatile organics in general (Bidleman, 1988). Furthermore, this is in 

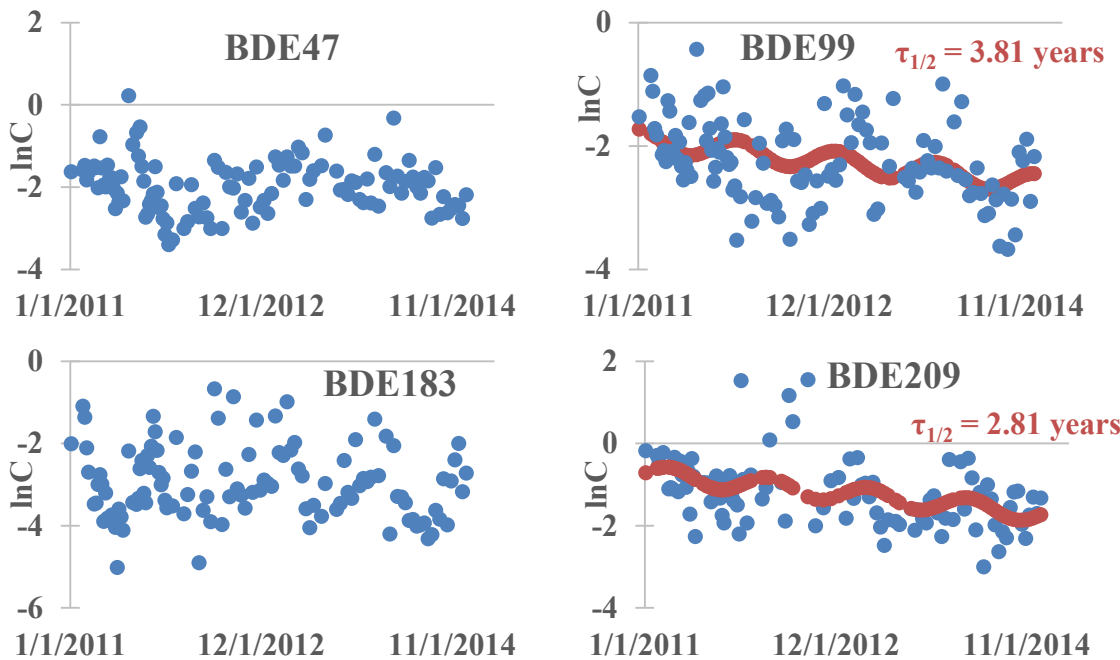

$1 / 1 / 2011$

$12 / 1 / 2012$

$11 / 1 / 2014$

Figure 4. Multi-year trends of the most abundant PBDEs.

agreement with a previous study conducted at a rural and an urban site in the Czech Republic, where higher particulate PBDE concentrations were also found in winter. This was attributed to temperature-induced shifts in gas-particle partitioning (Okonski et al., 2014). The higher degradation in summer and lower ABL height in winter may also support higher particulate PBDEs at cold temperatures. Additionally, Lee et al. (2004) proposed that low ambient air temperatures may cause increased emissions of PBDEs from anthropogenic activities such as combustion.

LRAT represents an important source of POPs such as PBDEs in background environments. The analysis of air mass history, as described in Sect. 2.5, was performed to identify potential source areas of PBDEs in central Europe. Air masses mainly originating from the west, south-west or north-west, i.e. air that has passed through the Atlantic Ocean or the North Sea, were found for 8 of the 10 samples with the lowest PBDE concentrations (Fig. S10). In contrast, the samples with $\Sigma_{8}$ PBDEs $>1 \mathrm{pg} \mathrm{m}^{-3}$ were not associated with air masses from a clear direction but rather by air that stagnated over continental Europe (Fig. S11). The fact that the highest PBDE concentrations were observed under advection from different directions suggests that there is a rather homogeneous continental emission source. The high PBDE concentrations observed in these samples are likely due to short and intense emissions of flame retardants, as for example during the incineration of products or waste-containing PBDEs.

In conclusion, the atmospheric concentrations of individual PBDEs were controlled by deposition processes (wet scavenging), meteorological parameters (ABL height, temperature) and LRAT, while the influence of revolatilization could not be demonstrated.

\subsection{Inter-annual and seasonal variations}

Several years following the inclusion of the penta- and octaBDE mixtures in the Stockholm Convention, long-term data can be used to assess whether the environmental levels are decreasing as a consequence of primary emissions reduction. The atmosphere is an ideal environmental compartment as it is particularly responsive to changes in primary emissions (Harrad, 2015).

To evaluate whether the atmospheric concentrations of individual PBDEs were significantly declining or not, the following harmonic regression as a function of time was used for this purpose (Liu et al., 2016; Venier et al., 2012):

$\ln C_{\mathrm{i}}=a_{0}+a_{1} \sin (z t)+a_{2} \cos (z t)+a_{3} t$,

where $C_{\mathrm{i}}$ is the concentration of individual BDE in a given sample, $t$ is the date when the sample was collected, $z=$ $2 \pi / 365.25$ which fixes the periodicity to 1 year, $a_{0}$ is an intercept that rectifies the units, $a_{1}$ and $a_{2}$ are harmonic coefficients that describe seasonal variations and $a_{3}$ is a firstorder rate constant (in days ${ }^{-1}$ ). The apparent halving or doubling time $\left(\tau_{1 / 2}\right)$ describes the time period it takes to reduce/increase the initial PBDE concentration to half/twice its value and should not be confused with half-lives related to degradation processes. It was calculated from $k$ as

$\tau_{1 / 2}=\ln 2 / k$.

The regression coefficients $a_{0}-a_{3}$ which were statistically significant $(p<0.05)$ are shown in Table S11.

Unlike a recent study in the North American Great Lakes region (Shunthirasingham et al., 2018), significant ( $p<$ 0.05 ) seasonality, characterized by the regression coefficients $a_{1}$ and $a_{2}$, were found for all congeners, except BDE85 (Table S11). Indeed, the regression coefficients for BDE28 and 
BDE209 show a maximum in spring and a minimum in autumn. On the other hand, higher concentrations in winter and lower in summer were found for most PBDEs (i.e. BDE99, BDE100, BDE153, BDE154 and BDE183), while the opposite seasonal trend was observed for BDE47. For the more brominated congeners (except BDE209), revolatilization is insignificant and the effect of the ABL height is dominating.

The seasonal variations presented here are in contradiction with many previous studies which reported higher concentrations of most PBDEs in summer compared to winter, with the exception of BDE209 (e.g. Birgul et al., 2012; Cetin and Odabasi, 2008). Another study, based in Japan (Dien et al., 2015), found higher concentrations of lower brominated congeners (BDE47 and BDE99) in the warm season, while concentrations of the higher brominated congeners which are mainly bound to particles (e.g. BDE183 and BDE209) peaked in winter. The PBDE summer maxima found in the Mediterranean (Birgul et al., 2012; Cetin and Odabasi, 2008) might be related to higher temperatures there, throughout all seasons, which may enhance the revolatilization from surfaces.

By applying Eq. (9) to all samples, significant decreases at the $95 \%$ confidence interval were found for BDE99, BDE100, BDE153 and BDE209 with apparent half-lives of 3.81, 2.97, 4.83 and 2.81 years, respectively (Figs. 4 and S12 and Table S12), but not for the remaining congeners. Previous research performed on the long-term trends of PBDEs in the atmosphere is mainly available for the UK and North America. Indeed, at different UK and Norwegian background sites, Schuster et al. (2010) reported significant decreases at 4 of the 11 sites investigated in 2000-2008 of BDE47, BDE99, BDE100, BDE153 and BDE154, with half-lives of 1.4-4.0 years. At two urban sites in UK, significant decreases were also found for $\Sigma_{9}$ PBDEs, with half-lives of 2.0 3.4 years (Birgul et al., 2012). Similarly, at two sites around the Canadian Great Lakes, PBDE concentrations were found to decrease slowly, with half-lives in the range of 2-16 years and faster decline rates at the sites closest to urban areas (Shunthirasingham et al., 2018). Other studies also reported significant decrease of PBDEs at three UK sites in 20002010 (Graf et al., 2016), but also in Japan in 2009-2012 (Dien et al., 2015). On the other hand, at a rural site in the UK, no clear and consistent decline in PBDE concentrations was found (Birgul et al., 2012), while around the American Great Lakes, the PBDE concentrations were decreasing at two urban sites, but were generally unchanged at three remote sites in 2005-2013 (Liu et al., 2016).

Overall, the results from the present study tend to show that the primary emissions of BDE99, 100, 153 and 209 are declining in central Europe. The similar rate of declines observed for other European sites (Table S12) indicates that regional-scale primary emissions are controlling the trends (Schuster et al., 2010). This is the first study reporting significant decreases only for some of the high brominated congeners but not for the low ones, which have lower first-order removal rates (Wei et al., 2013). However, though decreasing trends of some congeners are observed in different locations worldwide, we should keep in mind that PBDEs are still persisting in the environment and that a time lag is needed to clearly see the effect of reduction in primary emissions on background atmospheric concentrations of all PBDEs (Ma et al., 2013).

Interestingly, BDE28 showed an overall increasing trend, although this was only statistically significant at the $90 \%$ confidence interval (Fig. S12). Similarly, in the Great Lakes area (USA), Ma et al. (2013) found that the gaseous concentrations of BDE47 and BDE99 significantly increased from 2005 to 2011 at three rural/remote sites, with longer doubling times for BDE47 (7-9.4 years) compared to BDE99 (4.3-4.7 years) (Table S12). Taking this into account and considering that BDE28 is a product of the debromination of higher BDE congeners (Vesely et al., 2015; Wei et al., 2013), this is an additional indication that photolytic degradation of higher to lower brominated congeners is occurring in the atmosphere. Results from a modelling study concluded that $13 \%$ of the penta-BDE occurring in the environment resulted from the degradation of deca-BDE induced by photolysis (Schenker et al., 2008). The authors argued that once the penta mixture would be phased out completely, the importance of deca-BDE as a source of penta-BDE will increase. Here, we would argue that over the next decades, an increase or a steady state in the atmospheric concentrations of low brominated PBDEs may occur and that the congener profile will likely be dominated by those lighter congeners which are more prone to revolatilization (and have a higher persistency) and hence have a higher potential for long-range atmospheric transport. The fact that, in this study, no significant decrease was observed for BDE47 in comparison to BDE99, even though it originates from the same penta mixture and is known to be a debromination product of BDE99 (BezaresCruz et al., 2004), supports this hypothesis. However, monitoring air concentrations over a longer time span is needed to provide further evidence.

\section{Conclusions}

This study has shown that atmospheric PBDE levels are governed by deposition processes, meteorological parameters and LRAT.

One important finding of this study is the seasonal variation of the particulate fraction which was observed for most PBDEs. This has implications for studies using a passive sampling design for which the efficiency of particulate collection is still uncertain. Therefore, the interpretation of the seasonal variations of PBDEs from such studies should be done in a cautious manner, distinguishing whether the increased concentrations are due to a gas-particle partitioning shift or to increased secondary emissions. Moreover, one should keep in mind that the congener profiles observed in 
this study differed between the gaseous and the particulate phase; using a sampler collecting only one specific phase would provide a different congener profile.

Additionally, this study has shown that, at the current state of knowledge, none of the available models (i.e. $K_{\mathrm{OA}}$, steady state and QSPR) were able to effectively characterize the gas-particle partitioning of PBDEs. Though some of the tested models provided acceptable predictions for some of the compounds, none were satisfactory for all PBDEs investigated and for the specific conditions at this sampling site. This highlights the need for a gas-particle partitioning scheme for PBDEs that would be universally applicable under a range of atmospheric conditions. This is the minimal criterion to be able to adequately characterize the environmental fate of PBDEs at a global scale.

Finally, the results from this study tend to show that the debromination from high to low brominated congeners, enhanced by photolysis, is also an important process governing PBDE concentrations in the atmosphere. Given that nowadays, all formulations have been phased out, we may expect an enrichment in light congeners in the environment at a global scale. As these compounds are more volatile and have higher persistency than heavier congeners, their secondary formation enhanced by photolysis may be a serious issue of concern. Further studies should confirm whether the atmospheric concentrations of lower brominated PBDEs will increase or be at a steady state within the next decades.

Data availability. Description of samples collected, results of the breakthrough analysis, summary of individual PBDE concentrations and results of the correlation analyses are provided in the Supplement.

\section{The Supplement related to this article is available online at https://doi.org/10.5194/acp-18-12877-2018- supplement.}

Author contributions. JK and GL conceived the study. PK did the chemical analysis of samples. CD and GL designed and CD and JW performed the modelling of gas-particle partitioning. CD, JW and GL discussed the results. CD wrote the manuscript with input from all co-authors.

Competing interests. The authors declare that they have no conflict of interest.

Acknowledgements. This work was carried out with the support of National Sustainability Programme of the Ministry of Education, Youth and Sports (MEYS) of the Czech Republic (LO1214) and the RECETOX (LM2015051) and ACTRIS (LM2015037) research infrastructures funded by the MEYS and the European Structural and Investment Funds (CZ.02.1.01/0.0/0.0/16_013/0001761 and
CZ.02.1.01/0.0/0.0/16_013/0001315). The authors are thankful to Roman Prokeš (MU) for the field measurements, Jiří Kalina (MU) for help with statistics and Milan Váña (Czech Hydrometeorological Institute) for support with the data.

Edited by: Joel Thornton

Reviewed by: Hayley Hung and two anonymous referees

\section{References}

Agrell, C., ter Schure, A. F. H., Sveder, J., Bokenstrand, A., Larsson, P., and Zegers, B. N.: Polybrominated diphenyl ethers (PBDES) at a solid waste incineration plant I?: Atmospheric concentrations, Atmos. Environ., 38, 5139-5148, https://doi.org/10.1016/j.atmosenv.2004.05.024, 2004.

Allen, J. G., McClean, M. D., Stapleton, H. M., Nelson, J. W., and Webster, T. F.: Personal exposure to Polybrominated Diphenyl Ethers (PBDEs) in residential indoor air, Environ. Sci. Technol., 41, 4574-4579, 2007.

Besis, A. and Samara, C.: Polybrominated diphenyl ethers (PBDEs) in the indoor and outdoor environments - A review on occurrence and human exposure, Environ. Pollut., 169, 217-229, https://doi.org/10.1016/j.envpol.2012.04.009, 2012.

Besis, A., Botsaropoulou, E., Voutsa, D., and Samara, C.: Particle-size distribution of polybrominated diphenyl ethers (PBDEs) in the urban agglomeration of Thessaloniki, northern Greece, Atmos. Environ., 104, 176-185, https://doi.org/10.1016/j.atmosenv.2015.01.019, 2015.

Besis, A., Voutsa, D., and Samara, C.: Atmospheric occurrence and gas-particle partitioning of PBDEs at industrial, urban and suburban sites of Thessaloniki, northern Greece?: Implications for human health, Environ. Pollut., 215, 113-124, https://doi.org/10.1016/j.envpol.2016.04.093, 2016.

Besis, A., Lammel, G., Kukučka, P., Samara, C., Sofuoglu, A., Dumanoglu, Y., Eleftheriadis, K., Kouvarakis, G., Sofuoglu, S. C., Vassilatou, V., and Voutsa, D.: Polybrominated diphenyl ethers (PBDEs) in background air around the Aegean: implications for phase partitioning and size distribution, Environ. Sci. Pollut. Res., 24, 28102-28120, https://doi.org/10.1007/s11356-0170285-7, 2017.

Bezares-Cruz, J., Jafvert, C. T., and Hua, I.: Solar photodecomposition of decabromodiphenyl ether: Products and quantum yield, Environ. Sci. Technol., 38, 4149-4156, https://doi.org/10.1021/es049608o, 2004.

Bidleman, T. F.: Atmospheric processes, Environ. Sci. Technol., 22, 361-367, https://doi.org/10.1021/es00169a002, 1988.

Bidleman, T. F. and Tysklind, M.: Breakthrough during air sampling with polyurethane foam: What do PUF 2/PUF 1 ratios mean?, Chemosphere, 192, 267-271, https://doi.org/10.1016/j.chemosphere.2017.10.152, 2018.

Bidleman, T. F., Billings, W. N. and Foreman, W. T.: Vaporparticle partitioning of semivolatile organic compounds: estimates from field collections, Environ. Sci. Technol., 20, 10381043, https://doi.org/10.1021/es00152a013, 1986.

Birgul, A., Katsoyiannis, A., Gioia, R., Crosse, J., Earnshaw, M., Ratola, N., Jones, K. C., and Sweetman, A. J.: Atmospheric polybrominated diphenyl ethers (PBDEs) 
in the United Kingdom, Environ. Pollut., 169, 105-111, https://doi.org/10.1016/j.envpol.2012.05.005, 2012.

Cetin, B. and Odabasi, M.: Air-water exchange and dry deposition of polybrominated diphenyl ethers at a coastal site in Izmir Bay , Turkey, Environ. Sci. Technol., 41, 785-791, 2007.

Cetin, B. and Odabasi, M.: Atmospheric concentrations and phase partitioning of polybrominated diphenyl ethers (PBDEs) in Izmir, Turkey, Chemosphere, 71, 1067-78, 2008.

Chen, L.-G., Mai, B.-X., Bi, X.-H., Chen, S.-J., Wang, X.-M., Ran, Y., Luo, X.-J., Sheng, G.-Y., Fu, J.-M., and Zeng, E. Y.: Concentration levels, compositional profiles, and gas-particle partitioning of polybrominated diphenyl ethers in the atmosphere of an urban city in South China, Environ. Sci. Technol., 40, 11901196, https://doi.org/10.1021/es052123v, 2006.

Davie-Martin, C. L., Hageman, K. J., Chin, Y., Nistor, J. B., and Hung, H.: Concentrations, gas-particle distributions, and source indicator analysis of brominated flame retardants in air at Toolik Lake , Arctic Alaska, Environ. Sci. Process. Impacts, 18, 12741284, https://doi.org/10.1039/C6EM00395H, 2016.

Degrendele, C., Audy, O., Hofman, J., Kučerik, J., Kukučka, P., Mulder, M. D., Pribylova, P., Prokes, R., Sanka, M., Schaumann, G., and Lammel, G.: Diurnal Variations of Air-Soil Exchange of Semivolatile Organic Compounds (PAHs, PCBs, OCPs, and PBDEs) in a Central European Receptor Area, Environ. Sci. Technol., 50, 4278-4288, https://doi.org/10.1021/acs.est.5b05671, 2016.

Dien, N. T., Hirai, Y., Miyazaki, T., and Sakai, S.-I.: Factors influencing atmospheric concentrations of polybrominated diphenyl ethers in Japan, Chemosphere, 144, 2073-2080, https://doi.org/10.1016/j.chemosphere.2015.10.119, 2015.

Dien, N. T., Hirai, Y., and Sakai, S.-I.: Correlation between atmospheric boundary layer height and polybrominated diphenyl ether concentrations in air, Environ. Sci. Technol., 51, 356-364, https://doi.org/10.1021/acs.est.6b03004, 2017.

Ding, N., Chen, X., and Wu, C.-M. L.: Interactions between polybrominated diphenyl ethers and graphene surface: a DFT and MD investigation, Environ. Sci. Nano, 1, 55-63, https://doi.org/10.1039/C3EN00037K, 2014.

El-Zanan, H. S., Lowenthal, D. H., Zielinska, B., Chow, J. C., and Kumar, N.: Determination of the organic aerosol mass to organic carbon ratio in IMPROVE samples, Chemosphere, 60, 485-496, https://doi.org/10.1016/j.chemosphere.2005.01.005, 2005.

Eriksson, J., Green, N., Marsh, G., and Bergman, Å.: Photochemical decomposition of 15 polybrominated diphenyl ether congeners in methanol/water, Environ. Sci. Technol., 38, 31193125, https://doi.org/10.1021/es049830t, 2004.

Fang, L., Huang, J., Yu, G., and Wang, L.: Photochemical degradation of six polybrominated diphenyl ether congeners under ultraviolet irradiation in hexane, Chemosphere, 71, 258-267, https://doi.org/10.1016/j.chemosphere.2007.09.041, 2008.

Graf, C., Katsoyiannis, A., Jones, K. C., and Sweetman, A. J.: The TOMPs ambient air monitoring network - Continuous data on UK air quality for over 20 years, Environ. Pollut., 217, 42-51, https://doi.org/10.1016/j.envpol.2016.01.033, 2016.

Hafner, W. D. and Hites, R. A.: Effects of Wind and Air Trajectory Directions on Atmospheric Concentrations of Persistent Organic Pollutants near the Great Lakes, Environ. Sci Technol, 39, 78177825, https://doi.org/10.1021/es0502223, 2005.
Harner, T. and Bidleman, T. F.: Measurement of octanol-air partition coefficients for polycyclic aromatic hydrocarbons and polychlorinated naphthalenes, J. Chem. Eng. Data, 43, 40-46, https://doi.org/10.1021/je970175x, 1998a.

Harner, T. and Bidleman, T. F.: Octanol-air partition coefficient for describing particle/gas partitioning of aromatic compounds in urban air, Environ. Sci. Technol., 32, 1494-1502, https://doi.org/10.1021/es970890r, 1998b.

Harner, T. and Shoeib, M.: Measurements of octanol-air partition coefficients (KOA) for polybrominated diphenyl Ethers (PBDEs): Predicting partitioning in the environment, J. Chem. Eng. Data, 47, 228-232, https://doi.org/10.1021/je010192t, 2002.

Harrad, S.: A meta-analysis of recent data on UK environmental levels of POP-BFRs in an international context?: Temporal trends and an environmental budget, Emerg. Contam., 1, 39-53, https://doi.org/10.1016/j.emcon.2015.08.001, 2015.

Hoff, R. M., Brice, K. A., and Halsall, C. J.: Nonlinearity in the slopes of Clausius-Clapeyron plots for SVOCs, Environ. Sci. Technol., 32, 1793-1798, 1998.

Holoubek, I., Klánová, J., Jarkovský, J., and Kohoutek, J.: Trends in background levels of persistent organic pollutants at Kosetice observatory, Czech Republic. Part I. Ambient air and wet deposition 1996-2005, J. Environ. Monit., 9, 557-563, 2007.

Iacovidou, E., Mandalakis, M., and Stephanou, E. G.: Occurrence and diurnal variation of polychlorinated biphenyls and polybrominated diphenyl ethers in the background atmosphere of Eastern Mediterranean, Chemosphere, 77, 1161-1167, https://doi.org/10.1016/j.chemosphere.2009.09.043, 2009.

La Guardia, M. J., Hale, R. C., and Harvey, E.: Detailed polybrominated diphenyl ether (PBDE) congener composition of the widely used Penta-, Octa-, and Deca-PBDE technical flameretardant mixtures, Environ. Sci. Technol., 40, 6247-6254, https://doi.org/10.1021/es060630m, 2006.

Law, R. J., Herzke, D., Harrad, S., Morris, S., Bersuder, P., and Allchin, C. R.: Levels and trends of HBCD and BDEs in the European and Asian environments, with some information for other BFRs, Chemosphere, 73, 223-241, https://doi.org/10.1016/j.chemosphere.2008.02.066, 2008.

Lee, R. G. M., Thomas, G. O., and Jones, K. C.: PBDEs in the Atmosphere of Three Locations in Western Europe, Environ. Sci. Technol., 38, 699-706, 2004.

Li, Y.-F., Qiao, L., Ren, N., Sverko, E., Mackay, D., and Macdonald, R. W.: Decabrominated diphenyl ethers (BDE-209) in Chinese and global air: levels, gas/particle partitioning, and long-range transport: Is long-range transport of BDE-209 really governed by the movement of particles?, Environ. Sci. Technol., 51, 10351042, https://doi.org/10.1021/acs.est.6b05395, 2016.

Li, Y.-F., Ma, W.-L., and Yang, M.: Prediction of gas/particle partitioning of polybrominated diphenyl ethers (PBDEs) in global air: A theoretical study, Atmos. Chem. Phys., 15, 1669-1681, https://doi.org/10.5194/acp-15-1669-2015, 2015.

Ligocki, M. P., Leuenberger, C., and Pankow, J. F.: Trace organic compounds in rain. III. Particle scavenging of neutral organic compounds, Atmos. Environ., 19, 1619-1626, 1985.

Liu, L., Salamova, A., Venier, M., and Hites, R. A.: Trends in the levels of halogenated fl ame retardants in the Great Lakes atmosphere over the period 2005-2013, Environ. Int., 92-93, 442449, https://doi.org/10.1016/j.envint.2016.04.025, 2016. 
Lohmann, R. and Lammel, G.: Adsorptive and absorptive contributions to the gas-particle partitioning of polycyclic aromatic hydrocarbons: State of knowledge and recommended parametrization for modeling, Environ. Sci. Technol., 38, 3793-3803, https://doi.org/10.1021/es035337q, 2004.

Luo, P., Ni, H., Bao, L., Li, S., and Zeng, E. Y.: Size distribution of airborne particle-bound polybrominated diphenyl ethers and its implications for dry and wet deposition, Environ. Sci. Technol., 48, 13793-13799, 2014.

Ma, Y., Salamova, A., Venier, M., and Hites, R. A.: Has the phaseout of PBDEs affected their atmospheric levels? Trends of PBDEs and their replacements in the Great Lakes, Environ. Sci. Technol., 47, 11457-11464, 2013.

Mandalakis, M., Besis, A., and Stephanou, E. G.: Particle-size distribution and gas/particle partitioning of atmospheric polybrominated diphenyl ethers in urban areas of Greece, Environ. Pollut., 157, 1227-1233, https://doi.org/10.1016/j.envpol.2008.12.010, 2009.

Melymuk, L., Bohlin-Nizzetto, P., Sáňka, O., Pozo, K., and Klánová, J.: Current challenges in air sampling of semi-volatile organic contaminants: sampling artifacts and their influence on data comparability, Environ. Sci. Technol., 48, 14077-14091, https://doi.org/10.1021/es502164r, 2014.

Moeckel, C., Gasic, B., MacLeod, M., Scheringer, M., Jones, K. C., and Hungerbühler, K.: Estimation of the source strength of polybrominated diphenyl ethers based on their diel variability in air in Zurich, Switzerland, Environ. Sci. Technol., 44, 4225-3421, https://doi.org/10.1021/es1001049, 2010.

Möller, A., Xie, Z. Y., Sturm, R., and Ebinghaus, R.: Polybrominated diphenyl ethers (PBDEs) and alternative brominated flame retardants in air and seawater of the European Arctic, Environ. Pollut., 159, 1577-1583, https://doi.org/10.1016/j.envpol.2011.02.054, 2011.

Mulder, M. D., Heil, A., Kukučka, P., Kuta, J., Přibylová, P., Prokeš, R., and Lammel, G.: Long-range atmospheric transport of PAHs , PCBs and PBDEs to the central and eastern Mediterranean and changes of PCB and PBDE congener patterns in summer 2010, Atmos. Environ., 111, 51-59, https://doi.org/10.1016/j.atmosenv.2015.03.044, 2015.

Okonski, K., Degrendele, C., Melymuk, L., Landlová, L., Kukučka, P., Vojta, Š., Jiri, K., Čupr, P., and Klánová, J.: Particle size distribution of halogenated flame retardants and implications for atmospheric deposition and transport, Environ. Sci. Technol., 48, 14426-14434, 2014.

Pankow, J. F.: Review and comparative analysis of the theories on partitioning between the gas and aerosol particulate phases in the atmosphere, Atmos. Environ., 21, 2275-2283, https://doi.org/10.1016/0004-6981(87)90363-5, 1987.

Raff, J. D. and Hites, R. A.: Deposition versus photochemical removal of PBDEs from lake superior air, Environ. Sci. Technol., 41, 6725-6731, https://doi.org/10.1021/es070789e, 2007.

Salamova, A. and Hites, R. A.: Discontinued and alternative brominated flame retardants in the atmosphere and precipitation from the Great Lakes Basin, Environ. Sci. Technol., 45, 8698-8706, 2011.

Sanchez-Prado, L., Llompart, M., Lores, M., Garcia-Jares, C., and Cela, R.: Investigation of photodegradation products generated after UV-irradiation of five polybrominated diphenyl ethers using photo solid-phase microextraction, J. Chromatogr. A, 1071, 8592, https://doi.org/10.1016/j.chroma.2004.10.065, 2005.

Schenker, U., Soltermann, F., Scheringer, M., and Hungerbühler, K.: Modeling the environmental fate of polybrominated diphenyl ethers (PBDEs): The importance of photolysis for the formation of ligher PBDEs, Environ. Sci. Technol., 42, 9244-9249, 2008.

Schuster, J. K., Gioia, R., Breivik, K., Steinnes, E., Scheringer, M., and Jones, K. C.: Trends in European background air reflect reductions in primary emissions of PCBs and PBDEs, Environ. Sci. Technol., 44, 6760-6766, https://doi.org/10.1021/es101009x, 2010.

Shahpoury, P., Lammel, G., Holubová Šmejkalová, A., Klánová, J., Pribylová, P., and Vána, M.: Polycyclic aromatic hydrocarbons, polychlorinated biphenyls, and chlorinated pesticides in background air in central Europe - investigating parameters affecting wet scavenging of polycyclic aromatic hydrocarbons, Atmos. Chem. Phys., 15, 1795-1805, https://doi.org/10.5194/acp15-1795-2015, 2015.

Shahpoury, P., Lammel, G., Albinet, A., Sofuoglu, A., Dumanoğlu, Y., Sofuoglu, S. C., Wagner, Z., and Ždimal, V.: Evaluation of a conceptual model for gas-particle partitioning of polycyclic aromatic hydrocarbons using polyparameter linear free energy relationships, Environ. Sci. Technol., 50, 12312-12319, https://doi.org/10.1021/acs.est.6b02158, 2016.

Shunthirasingham, C., Alexandrou, N., Brice, K. A., DryfhoutClark, H., Su, K., Shin, C., Park, R., Pajda, A., Noronha, R., and Hung, H.: Temporal trends of halogenated flame retardants in the atmosphere of the Canadian Great Lakes Basin (2005-2014), Environ. Sci. Impacts, 20, 469-479, https://doi.org/10.1039/C7EM00549K, 2018.

Söderström, G., Sellström, U., De Wit, C. A., and Tysklind, M.: Photolytic debromination of decabromodiphenyl ether (BDE 209), Environ. Sci. Technol., 38, 127-132, https://doi.org/10.1021/es034682c, 2004.

Stohl, A., Forster, C., Frank, A., Seibert, P., and Wotawa, G.: Technical note: The Lagrangian particle dispersion model FLEXPART version 6.2, Atmos. Chem. Phys., 5, 2461-2474, https://doi.org/10.5194/acp-5-2461-2005, 2005.

Strandberg, B., Dodder, N. G., Basu, I., and Hites, R. A.: Concentrations and spatial variations of polybrominated diphenyl ethers and other organohalogen compounds in Great Lakes air, Environ. Sci. Technol., 35, 1078-83, 2001.

Su, Y., Hung, H., Brice, K. A., Su, K., Alexandrou, N., Blanchard, P., Chan, E., Sverko, E., and Fellin, P.: Air concentrations of polybrominated diphenyl ethers (PBDEs) in 2002-2004 at a rural site in the Great Lakes, Atmos. Environ., 43, 6230-6237, https://doi.org/10.1016/j.atmosenv.2009.08.034, 2009.

ter Schure, A. F. H., Larsson, P., Agrell, C., and Boon, J. P.: Atmospheric transport of polybrominated diphenyl ethers and polychlorinated biphenyls to the Baltic Sea, Environ. Sci. Technol., 38, 1282-1287, https://doi.org/10.1021/es0348086, 2004.

UNEP: Report of the Conference of the Parties of the Stockholm Convention on Persistent Organic Pollutants on the Work of its Fourth Meeting, available at: www.chm.pops.int (last access: 10 January 2018), 2009.

Venier, M. and Hites, R. A.: Atmospheric deposition of PBDEs to the Great Lakes featuring a Monte Carlo analysis of errors, Environ. Sci. Technol., 42, 9058-9064, https://doi.org/10.1021/es8008985, 2008. 
Venier, M., Hung, H., Tych, W., and Hites, R. A.: Temporal Trends of Persistent Organic Pollutants: A Comparison of Different Time Series Models, Environ. Sci. Technol., 46, 3928-3934, https://doi.org/10.1021/es204527q, 2012.

Vesely, M., Vajglova, Z., Kotas, P., Kristal, J., Ponec, R., and Jiricny, V.: Model for photodegradation of polybrominated diphenyl ethers, Environ. Sci. Pollut. Res., 22, 4949-4963, https://doi.org/10.1007/s11356-014-3741-7, 2015.

Wania, F., Axelman, J., and Broman, D.: A review of processes involved in the exchange of persistent organic pollutants across the air-sea interface, Environ. Pollut., 102, 3-23, https://doi.org/10.1016/s0269-7491(98)00072-4, 1998a.

Wania, F., Haugen, J.-E., Lei, Y. D., and Mackay, D.: Temperature dependence of atmospheric concentrations of semivolatile organic compounds, Environ. Sci. Technol., 32, 1013-1021, https://doi.org/10.1021/es970856c, 1998b.
Webster, F. T., Harrad, S., Millette, J. R., Holbrook, R. D., Davis, J. M., Stapleton, H. M., Allen, J. G., McClean, M. D., Ibarra, C., Abdallah, M. A.-E., and Covaci, A.: Identifying transfer mechanisms and sources of decabromodiphenyl ether (BDE 209) in indoor environments using environmental forensic microscopy, Environ. Sci. Technol., 43, 3067-3072, 2009.

Wei, H., Zou, Y., Li, A., Christensen, E. R., and Rockne, K. J.: Photolytic debromination pathway of polybrominated diphenyl ethers in hexane by sunlight, Environ. Pollut., 174, 194-200, https://doi.org/10.1016/j.envpol.2012.11.035, 2013.

Wei, X., Yuan, Q., Serge, B., Xu, T., Ma, G., and Yu, H.: In silico investigation of gas/particle partitioning equilibrium of polybrominated diphenyl ethers (PBDEs), Chemosphere, 188, 110 118, https://doi.org/10.1016/j.chemosphere.2017.08.146, 2017.

Yue, C. Y. and Li, L. Y.: Filling the gap: Estimating physicochemical properties of the full array of polybrominated diphenyl ethers (PBDEs), Environ. Pollut., 180, 312-323, https://doi.org/10.1016/j.envpol.2013.05.029, 2013. 